\title{
Perancangan Fasilitas Kerja Proses Pengelasan yang Ergonomis dengan Menggunakan Metode Design For Manufacture And Assembly (DFMA) di Bengkel Las Wen
}

\author{
Nofirza, Anwardi, Rika dan Fajar Sidik Rudini*) \\ Jurusan Teknik Industri, Fakultas Sains dan Teknologi, UIN Sultan Syarif Kasim Riau \\ J1. HR. Soebrantas No. 155 Simpang Baru, Panam, Pekanbaru, 28293, Indonesia
}

DOI: 10.20961/performa.18.1.29824

\begin{abstract}
Abstrak
Usaha bengkel las “wen” melakukan pekerjaan las dengan postur kerja yang tidak baik sehingga menyebabkan cedera otot (Musculoskeletal Disorders). Untuk itu perlu dirancang sebuah fasilitas kerja untuk proses pengelasan yang efisien. Kuesioner Nordic Body Map (NBM) digunakan untuk mengetahui bagian tubuh mana saja yang mengalami keluhan tidak sakit, cukup sakit, sakit dan evaluasi menggunakan metode REBA (Rapid Entire Body Assessment) menjadi input untuk memperbaiki postur kerja operator menjadi lebih baik. Perancangan fasilitas pengelasan dilakukan dengan menggunakan metode Design For Manufacture and Assembly (DFMA) karena dapat mengevaluasi biaya dan material fasilitas perancangan baru dengan fasilitas perancangan yang sudah ada sebelumnya dalam tahap pengujian. Hasil rancangan berupa meja kerja yang memiliki pijakan kaki, tempat kawat las, tempat peletakan material, tempat busur dan ragum dalam satu fasilitas, berdasarkan pengujian diperoleh hasil skor REBA lebih rendah sehingga postur kerja menjadi lebih baik, fasilitas dapat dimanfaatkan untuk mengelas semua produk pada bengkel las dan efisiensinya dibandingkan alat sebelumnya sebesar $35 \%$.
\end{abstract}

Kata kunci: Bengkel Las, Musculoskeletal Disorders, NBM, REBA, DFMA

\begin{abstract}
The "wen" welding workshop business does welding with bad work postures that cause muscle injury (Musculoskeletal Disorders). For this reason, it is necessary to design a work facility for an efficient welding process. The Nordic Body Map (NBM) questionnaire was used to find out which body parts had complaints that they were not sick, enough pain, illness and evaluation using the Rapid Entire Body Assessment (REBA) method to become an input to improve the operator's work posture to be better. The design of welding facilities is carried out using the Design For Manufacture and Assembly (DFMA) method because it can evaluate the costs and material of new design facilities with pre-existing design facilities in the testing phase. The design results are in the form of a workbench that has a footrest, a welding wire, a material laying place, a bow and vise in a facility, based on testing the lower the REBA score results so that the work posture is better, the facility can be used to weld all products to the workshop weld and efficiency compared to the previous tool at $35 \%$.
\end{abstract}

Keywords: Welding Workshop, Musculoskeletal Disorders, NBM, REBA, DFMA

\section{Pendahuluan}

Musculoskeletal Disorders merupakan salah satu cedera yang sering dialami pekerja dalam melakukan kegiatan Manual Material Handling (MMH) yaitu cedera pada otot, urat syaraf, urat daging, tulang, persendian tulang, tulang rawan yang disebabkan oleh aktivitas kerja (Dewi, 2017).

Dengan resiko pekerjaan yang dapat menyebabkan cedera tersebut maka perlu dilakukan evaluasi terhadap postur kerja operator sehingga dalam perbaikan dapat berkelanjutan (Continious Improvement), metode yang digunakan adalah Rapid Entire Body Assessment (REBA), penilaian postur kerja pada dua kategori. Kategori A menilai trunk (badan), neck (leher) dan legs (kaki). Sedangkan Kategori B menilai upper arms (lengan atas), lower arms (lengan bawah) dan wrists (pergelagan tangan) (Wibisono, 2017).

Perbaikan sistem kerja dapat dilakukan dengan banyak pendekatan, salah satunya Design for manufacture and assembly (DFMA). Design for manufacture and assembly (DFMA) adalah pendekatan yang digunakan untuk merancang produk yang berkualitas maksimum dan berbiaya minimum (Nasution, 2013).

Usaha bengkel las "wen" menyediakan jasa pengelasan berbagai jenis logam. Pada proses pekerjaan bengkel las terdapat 2 mesin utama seperti mesin las untuk penyambungan logam dan mesin gerinda tangan untuk pemotongan logam. Pada proses pengelasan, operator yang menggunakan mesin las dan gerinda tangan

*Korespondensi : fajarsidikrudinist@gmail.com 
cenderung tidak memperhatikan resiko yang terjadi ketika melakukan pekerjaan, baik itu dari alat, keselamatan kerja, maupun fasilitas kerja yang tersedia, dimana dalam proses pengelasan memakan waktu yang cukup lama, contohnya untuk produk teralis membutuhkan waktu " 4 jam" (estimasi), hal ini berpotensi menyebabkan cedera otot (Musculoskeletal Disorders) jika dibiarkan terus menerus. Oleh karena itu untuk menghindari resiko cedera maupun kecelakaan kerja dilakukan sebuah penelitian tentang perancangan fasilitas kerja proses pengelasan yang ergonomis di tempat usaha bengkel las wen ini.

Studi literatur fasilitas kerja proses pengelasan yang sudah ada sebelumnya merupakan hasil tugas akhir mahasiswa program studi sarjana teknik industri yang dibuat sultra retnawan suripto (2011) adalah merancang fasilitas kerja pengelasan pada las kecil (support), untuk kelengkapan fasilitas perancangan dari penelitian ini membuat peneliti mengambil referensi dari skripsi ini untuk dijadikan inovasi perancangan fasilitas pengelasan terbaru. Terdapat beberapa hal yang masih bisa dikembangkan yaitu: penyesuaian alat yang dapat mengelas berbagai ukuran produk, menambahkan tempat menjepitkan produk dan kepresisian ukuran maupun pemasangan bagian-bagian dari alat bantu las listrik, pemasangan benda kerja yang sederhana dan alternatif material yang digunakan bisa dipertimbangkan kelebihan dan kekurangannya masing-masing. Perancangan fasilitas pengelasan dilakukan dengan menggunakan metode Design For Manufacture and Assembly (DFMA) karena dapat mengevaluasi biaya dan material fasilitas perancangan baru dengan fasilitas perancangan yang sudah ada sebelumnya dalam tahap pengujian dengan tujuan untuk merancang dan mengimplementasikan fasilitas kerja proses pengelasan di bengkel las wen dan menguji keandalan dan efisiensi dari fasilitas kerja hasil rancangan.

\section{Metode Penelitian}

Langkah pertama dalam penelitian adalah dengan melakukan observasi dan wawancara langsung ke lapangan yang terkait dengan penelitian, informasi ini dapat berupa studi literatur.

Identifikasi masalah pada penelitian ini adalah untuk mengetahui persoalan, penyebab permasalahan, sekaligus solusi yang tepat untuk menyelesaikan masalah tersebut. Proses identifikasi masalah penting dilakukan agar rumusan masalah menjadi jelas. Penetapan identifikasi masalah bertujuan untuk mengetahui masalah-masalah yang ada pada Bengkel Las Wen.

Dalam penelitian ini data yang diperoleh adalah data primer dan data sekunder.

a. Data Primer

Data primer merupakan data yang diperoleh dari pengamatan dan penelitian secara langsung. Pengumpulan data primer ini dilakukan dengan mengamati secara langsung dan meminta keterangan serta mewawancarai operator las. Adapun data yang diperoleh adalah data keluhan pekerja dengan membagikan kusioner Nordic Body Map (NBM) merupakan kueisoner yang ditanyakan kepada operator las dengan wawancara untuk melihat tingkat keluhan rasa sakit yang diderita oleh operator las pada saat bekerja, kuesioner terbuka merupakan kuesioner yang diisi sesuai dengan pendapat operator las, skor reba dan data waktu proses produksi (estimasi).

b. Data Sekunder

Data sekunder adalah data yang digunakan sebagai data pendukung pada sebuah penelitian. Adapun data sekunder yang digunakan dalam penelitian ini adalah data material yang digunakan dan biaya fasilitas kerja.

Pada langkah ini penulis melakukan pengolahan data dari pengumpulan data yang dilakukan dengan melakukan sesuai dengan perumusan masalah yang telah dibuat untuk mencapai hasil sesuai dengan tujuan.

a. Perancangan Fasilitas Kerja

Data yang diperlukan dalam DFMA adalah analisa kebutuhan bahan, pembuatan sketsa desain awal, evaluasi desain, penyempurnaan desain akhir dan perancangan fasilitas kerja.

Adapun untuk menghitung faktor investasinya dapat dilakukan dengan menggunakan rumus sebagai berikut.

$R i=\frac{\text { Qes }}{W a}$

Bila perakitan telah selesai, data pada lembar kerja dijumlah untuk mendapatkan total estimasi waktu dan biaya manual assembly dan juga jumlah minimum komponen pada produk secara teori, akhirnya efisiensi desain dari manual assembly dicari dari rumus.

$\sum E m=\frac{3 \mathrm{NM}}{T m}$

b. Tahap Pengujian 
Dilakukan pengujian terhadap fasilitas kerja yang telah dirancang yaitu dengan evaluasi material yang digunakan, evaluasi biaya fasilitas kerja, evaluasi postur kerja dengan REBA (Rapid Entire Body Assessment) dan efisiensi hasil rancangan.

\section{Hasil dan Pembahasan}

Adapun hasil dan pembahasan sebagai berikut:

Combination table dapat dilakukan untuk mengetahui komponen penyusun suatu fasilitas yang akan digunakan dalam membuat beberapa konsep alternatif. Adapun komponen dari combination table yang akan dibuat dalam beberapa konsep sebagai berikut.

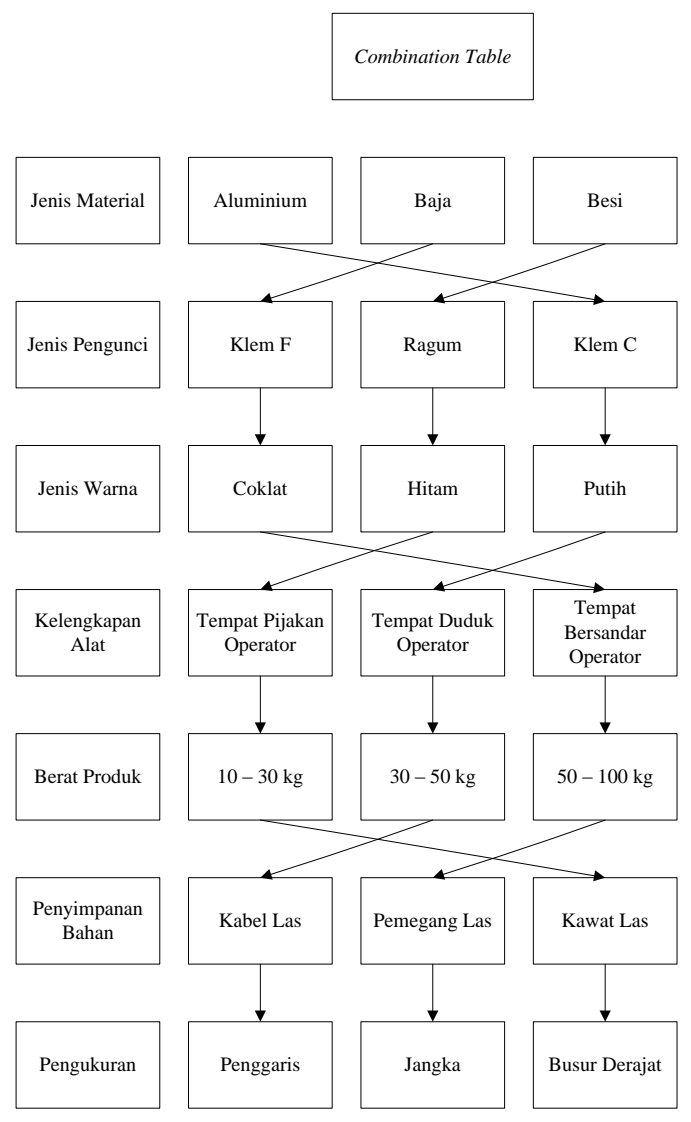

Gambar 1. Combination Table

Berdasarkan gambar 1 menunjukkan bahwa terdapat 3 konsep yang digunakan, yaitu konsep A, konsep B dan konsep C.

Penilaian beberapa konsep yang akan dipilih salah satu konsep memungkinkan untuk membawa kesuksesan pada sebuah produk. Adapun penilaian konsep yang akan dipilih sebagai berikut.

Tabel 1. Penilaian Konsep

\begin{tabular}{|c|c|c|c|c|c|}
\hline \multirow{2}{*}{ Kriteria } & \multirow{2}{*}{ Beban } & \multicolumn{2}{|c|}{ Konsep A } & \multicolumn{2}{|c|}{ Konsep B } \\
\hline & & Rating & Nilai Beban & Rating & Nilai Beban \\
\hline Jenis Material & $25 \%$ & 4 & 1 & 4 & 1 \\
\hline Jenis Pengunci & $15 \%$ & 3 & 0,45 & 3 & 0,45 \\
\hline Jenis Warna & $5 \%$ & 2 & 0,1 & 2 & 0,1 \\
\hline Kelengkapan Alat & $10 \%$ & 3 & 0,3 & 3 & 0,3 \\
\hline Berat Produk & $20 \%$ & 4 & 0,8 & 3 & 0,6 \\
\hline Penyimpanan Bahan & $15 \%$ & 4 & 0,6 & 3 & 0,45 \\
\hline Pengukuran & $10 \%$ & 3 & 0,3 & 3 & 0,3 \\
\hline Total Nilai & & \multicolumn{2}{|c|}{3,55} & \multicolumn{2}{|c|}{3,2} \\
\hline Peringkat & & \multicolumn{2}{|c|}{1} & \multicolumn{2}{|c|}{2} \\
\hline Lanjutkan? & & \multicolumn{2}{|c|}{$\mathrm{Ya}$} & \multicolumn{2}{|c|}{ Tidak } \\
\hline
\end{tabular}

Berdasarkan tabel 1 di atas menunjukkan konsep yang terpilih adalah konsep A.

Terjemahan kebutuhan bengkel las dilakukan untuk mengetahui bentuk dari desain konsep yang telah dipilih dapat digunakan secara maksimal dalam proses pengelasan di bengkel las. Adapun terjemahan kebutuhan bengkel las dapat dilihat sebagai berikut. 


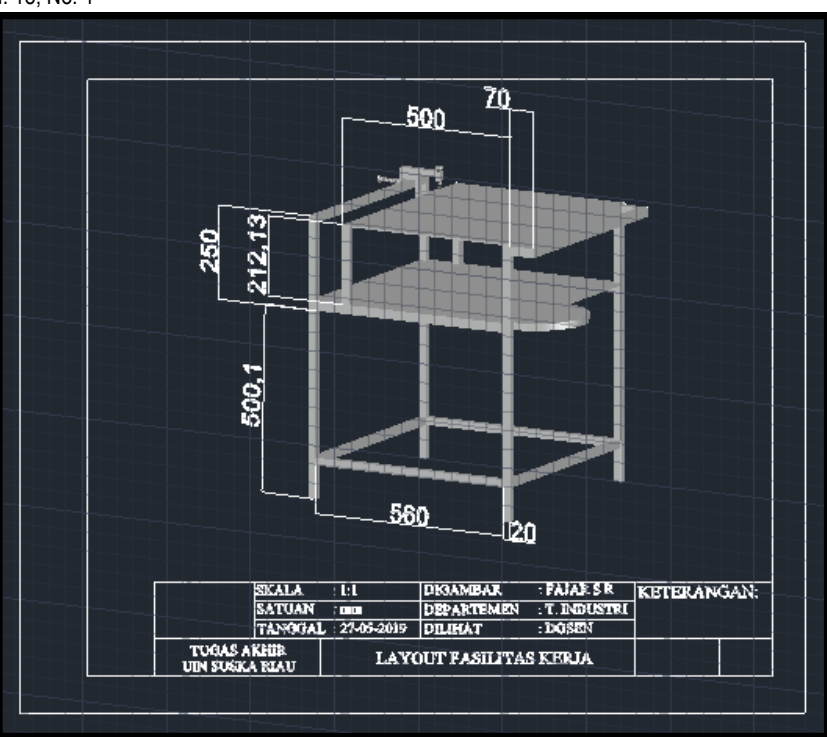

Gambar 2. Kesluruhan Desain

Dari gambar 2 di atas, konsep A terdiri atas kaki meja yang berfungsi sebagai tumpuan fasilitas kerja, meja dasar sebagai tempat untuk meletakkan material, ragum sebagai alat penjepit material, busur derajat sebagai pengatur berapa besar derajat material yang akan dikerjakan oleh operator las dan tempat penyimpanan kawat las, tiang penyangga sebagai tumpuan untuk landasan benda kerja dan bidang alas meja sebagai tempat meletakkan benda kerja.

Adapun biaya material perancangan sebesar $\mathrm{Rp} 415.000$ dan biaya non material sebesar $\mathrm{Rp} 250.000$, sehingga total biaya fasilitas kerja setelah perancangan sebesar Rp 665.000.

Proses perakitan biasanya merupakan proses yang paling banyak menghabiskan biaya produksi dan jumlah pekerja. Cara untuk menentukan metode yang tepat adalah menggunakan diagram pemilihan metode perakitan. Dalam menggunakan diagram dibutuhkan 6 data yang harus diketahui, adapun 6 data tersebut dapat dilihat sebagai berikut.

Tabel 2. Data Metode Perakitan

\begin{tabular}{|c|c|c|c|c|c|}
\hline Data & Simbol & Total Unit & Total Perubahan & Total Biaya & Total Shift \\
\hline Volume produksi per shift & Vs & 1 & - & - & - \\
\hline \multirow{6}{*}{$\begin{array}{l}\text { Jumlah komponen pada } \\
\text { rakitan }\end{array}$} & \multirow{6}{*}{$\mathrm{Na}$} & 27 & - & - & - \\
\hline & & 5 & - & - & - \\
\hline & & 1 & - & - & - \\
\hline & & 1 & - & - & - \\
\hline & & & & & \\
\hline & & 1 & - & - & - \\
\hline Satu atau banyak jenis & & & - & - & - \\
\hline $\begin{array}{c}\text { produk selama } 3 \text { tahun } \\
\text { pertama }\end{array}$ & $\mathrm{Np}$ & 1 & & & \\
\hline $\begin{array}{c}\text { Jumlah komponen yang } \\
\text { diperlukan untuk } \\
\text { modifikasi produk }\end{array}$ & $\mathrm{Nt}$ & 51 & - & - & - \\
\hline $\begin{array}{l}\text { Jumlah perubahan desain } \\
\text { yang diinginkan selama } 3 \\
\text { tahun umur produk }\end{array}$ & $\mathrm{Nd}$ & - & 17 & - & - \\
\hline $\begin{array}{l}\text { Pengeluaran investasi } \\
\text { yang diizinkan }\end{array}$ & & & & & \\
\hline $\begin{array}{l}\text { perusahaan untuk } \\
\text { mengganti } 1 \text { operator } \\
\text { pada } 1 \text { shift }\end{array}$ & Qe & - & - & $\mathrm{Rp} 57.000 .000$ & - \\
\hline $\begin{array}{c}\text { Biaya } 1 \text { operator } \\
\text { perakitan per tahun }\end{array}$ & Wa & - & - & Rp 60.000.000 & - \\
\hline Jumlah shift pekerja & Sh & - & - & & $1 \mathrm{shift}$ \\
\hline
\end{tabular}

Adapun untuk menghitung faktor investasinya dapat dilakukan dengan menggunakan rumus (1). 
$\mathrm{Ri}=\frac{\mathrm{Qes}}{\mathrm{Wa}}=\frac{57.000 .000 \times 1}{60.000 .000}=0,95$ atau $95 \%$

Dari perhitungan di atas dapat dilihat terjadi faktor investasi sebesar 0,95 (95\%), artinya terdapat 95\% faktor yang mempengaruhi investasi seperti keuntungan yang diperoleh dari penjualan produk. Data-data tersebut kemudian dimasukkan ke dalam diagram pemilihan metode perakitan.

Dari tabel 2 dapat dilihat metode perakitan yang tepat untuk perancangan fasilitas kerja proses pengelasan adalah Manual Assembly (MM) dengan mechanical assistence.

Berikut ini merupakan hasil rancangan berdasarkan perakitan yang tepat.

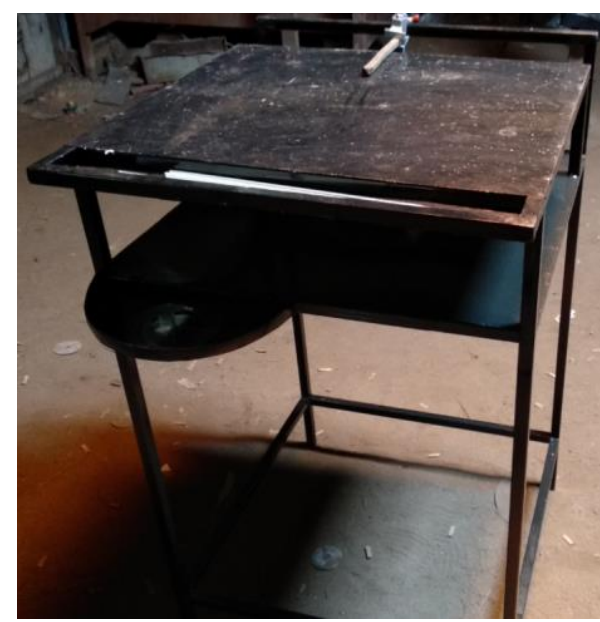

Gambar 3. Hasil Rancangan

Berdasarkan gambar 3 dapat dilihat hasil rancangan desain baru yang akan digunakan dalam fasilitas proses pengelasan yang ergonomis.

Adapun spesifikasi, dimensi dan cara menggunakan fasilitas ini sebagai berikut.

a. Spesifikasi fasilitas ini yaitu memiliki pijakan kaki yang digunakan untuk memudahkan operator ketika hendak mengistirahatkan kaki ketika lama berdiri, tersedia tempat peletakan busur derajat, tempat peletakan kawat las, bidang alas benda kerja dan tempat peletakan material yang akan di las, serta penjepit berupa ragum yang dapat menjepit benda kerja yang ingin di las.

b. Dimensi pada fasilitas kerja ini adalah memiliki tinggi sebesar $73 \mathrm{~cm}$, panjang dan lebar sebesar $\quad 60$ $\mathrm{cm}$.

c. Cara menggunakan fasilitas ini terkhusus pada penjepit benda kerja yaitu ragum, ragum dapat dipindahkan sesuai dengan keinginan operator las sehingga dapat di atur posisi nyaman operator dalam bekerja.

Dari evaluasi postur kerja setelah perancangan, didapat skor lebih rendah jika dibandingkan postur kerja sebelum perancangan, karena adanya fasilitas kerja dapat membuat pekerjaan menjadi lebih aman dan nyaman sehingga musculoskeletal disorders (cedera otot) dapat dihindari atau diminimalisir, adapun perbandingan skor reba sebelum dan setelah perancangan dapat dilihat sebagai berikut.

Tabel 3. Perbandingan rekapitulasi Skor REBA Operator Las

\begin{tabular}{ccccc}
\hline Operator & $\begin{array}{c}\text { Skor REBA Sebelum } \\
\text { Perancangan }\end{array}$ & Resiko & $\begin{array}{c}\text { Skor REBA Setelah } \\
\text { Perancangan }\end{array}$ & Resiko \\
\hline Operator 1 & 11 & Sangat Tinggi & 2 & Rendah \\
Operator 2 & 8 & Tinggi & 2 & Rendah \\
Operator 3 & 9 & Tinggi & 3 & Rendah \\
Operator 4 & 10 & Tinggi & 3 & Rendah \\
\hline
\end{tabular}

Dari tabel di atas dapat dilihat penurunan skor reba yang artinya pekerjaan menjadi lebih baik jika dibandingkan sebelumnya yang memiliki resiko pekerjaan yang tinggi.

Efisiensi hasil rancangan yang dihitung menggunakan stopwatch didapat dalam membuat produk teralis membutuhkan waktu sebagai berikut.

Tabel 4. Waktu Sample Hasil Rancangan

\begin{tabular}{cc}
\hline Sample & Waktu (menit) \\
\hline 1 & 153.20 .28 \\
\hline
\end{tabular}


Dari tabel di atas dapat dilihat setelah menggunakan hasil rancangan membutuhkan waktu rata-rata 153,85 menit atau 2,6 jam kerja yang sebelumnya membutuhkan waktu 4 jam (estimasi), karena adanya penurunan waktu yang diakibatkan oleh fasilitas kerja yang lebih sederhana untuk digunakan dan juga dilengkapi sesuai dengan kebutuhan yang diinginkan oleh operator sehingga pengerjaan dalam membuat produk teralis dapat dipersingkat. Kemudian dilakukan perbandingan efisiensi waktu sebagai berikut.

Efisiensi Waktu $=\frac{4-2,6}{4}=0,35 \times 100 \%=35 \%$

Dapat dilihat terdapat efisiensi waktu sebesar 35\% setelah menggunakan hasil rancangan. Kemudian dilakukan wawancara terhadap operator setelah menggunakan hasil rancangan terdapat kemudahan dalam melakukan pekerjaan seperti pengerjaan las menjadi lebih aman, nyaman dan lebih mempersingkat waktu dalam mencari material yang akan di las. Operator las merasa puas terhadap hasil rancangan karena tinggi fasilitas kerja sesuai dengan yang diharapkan sehingga tidak perlu jongkok ataupun membungkuk ketika melakukan proses pengelasan. Operator las lebih memilih berdiri dalam melakukan pekerjaan karena posisi ternyaman saat mengelas adalah posisi berdiri jika dibandingkan jongkok maupun duduk.

Setelah dilakukan perubahan desain pada setiap sub-rakitan, disusun lembar kerja yang baru untuk masingmasing sub-rakitan. Akhirnya didapat efisiensi total dari desain baru menggunakan rumus (2) sebagai berikut.

$$
\sum \mathrm{Em}=\frac{3 \mathrm{NM}}{\mathrm{Tm}}=\frac{3 \times 32}{300}=0,32 \text { atau } 32 \%
$$

Dapat dilihat bahwa terjadi efisiensi dalam desain baru sebesar 0,32 (32\%), artinya tingkat keberhasilan pada desain baru mencapai $32 \%$ karena adanya pengurangan komponen yang tidak diperlukan dan penambahan komponen yang dibutuhkan. Kenaikan efisiensi sebesar 0,04 (4\%) dari 0,28 (28\%) menjadi 0,32 (32\%), artinya dalam desain baru efisiensinya menjadi lebih baik.

Dilakukan perbandingan biaya operasi desain lama dan desain baru, terdapat perbandingan harga sebesar Rp 950.000, dari sebelumnya Rp 1.365.000 menjadi Rp 415.000, artinya terjadi penghematan biaya operasi dalam desain baru.

\section{Simpulan}

Adapun kesimpulan yang dapat diambil dari laporan penelitian di bengkel las wen adalah fasilitas kerja hasil rancangan berupa meja kerja yang memiliki pijakan kaki yang digunakan untuk memudahkan operator ketika hendak mengistirahatkan kaki ketika lama berdiri, tersedia tempat peletakan busur derajat, tempat peletakan kawat las, bidang alas benda kerja dan tempat peletakan material yang akan di las, serta penjepit berupa ragum yang dapat menjepit benda kerja yang ingin di las dengan tinggi sebesar $73 \mathrm{~cm}$, panjang dan lebar sebesar $60 \mathrm{~cm}$ dan cara menggunakan fasilitas ini terkhusus pada penjepit benda kerja yaitu ragum, ragum dapat dipindahkan sesuai dengan keinginan operator las sehingga dapat di atur posisi nyaman operator dalam bekerja. Dalam hasil rancangan ini dapat membuat operator las lebih aman dan nyaman dalam bekerja sehingga dapat terhindar dari musculoskeletal disorders (cedera otot) dan mempersingkat waktu pekerjaan. Berdasarkan pengujian diperoleh hasil skor REBA lebih rendah sehingga postur kerja menjadi lebih baik, fasilitas dapat dimanfaatkan untuk mengelas semua produk pada bengkel las dan efisiensinya dapat dipersingkat dari 4 jam menjadi 2,6 jam dibandingkan alat sebelumnya sebesar 35\%.

Adapun saran yang dapat diberikan dari penelitian adalah disarankan bagi perusahaan untuk selalu memperhatikan resiko pekerjaan yang tinggi dengan membuat resiko tersebut menjadi lebih rendah, untuk itu perlu implementasi fasilitas kerja yang telah dirancang. Bagi penelitian selanjutnya dengan adanya penelitian ini diharapkan dapat menjadi sumber ide bagi peneliti-peneliti yang ingin mendalami permasalahan ini selanjutnya. Dapat ditambahkan berupa meja yang bisa di naik dan diturunkan, meja yang dapat dipindah-pindahkan dan dilengkapi alat pemotong las. 


\section{Daftar Pustaka}

Achmad, M. Aplikasi Ergonomi Untuk Meningkatkan Kinerja Operator Dan Output Produksi Pada Proses Taper. Jurnal MATRIK, Vol. 14, No. 2. Maret 2014.

Arifah., D. A., dan Majid, A. Analisis Postur Kerja Pada Pekerjaan Manual Handling Di Area Workshop PT.X Dengan Menggunakan Metode REBA. Journal of Industrial Hygiene and Occupational Health, Vol. 2, No.2. April 2018.

Awasthi., N., Singh, P., dan Awasthi, S. Risk assessment of handloom weavers for musculoskeletal disorder in durrie unit. The Pharma Innovation Journal, Vol. 7, No.7. June 2018.

Dudung, A., April 2012. Merancang Produk. Cetakan Pertama. Remaja Rosdakarya. Bandung.

Felicia., Adianto., dan Widodo, L. Perbaikan Stasiun Kerja Packing Dan Carding Fiber Dacron (Polieti Lena Tereftalat) Untuk Mencegah Musculoskeletal Disorder (MSDs) Pada Pekerja PT. Xyz Cikupa Tangerang. Jurnal Ilmiah Teknik Industri, Vol. 5, No. 2. 2017.

Miko., H., Sopianah., Y., Wicaksena., B., Suroto., dan Ambarwati, T. Posture Work to Complaint Musculoskeletal Disorders at the Dentist. Journal of International Dental and Medical Research, Vol. 11, No. 1. 2018.

Nasution., A., B., Siregar., I., dan Ginting, R. Rancangan Perbaikan Produk Saklar Dengan Integrasi Metode Qfd Dan Dfma Di Pt Xxx. Jurnal UNDIP, Vol. 8, No. 3. September 2013.

Rachman., I., Sari., R. E., dan Sahara, P. Hubungan Aktifitas Berulang Dan Sikap Kerja Dengan Keluhan Muskuloskeletal Disorders Pada Tenaga Kerja di PT Bahari Gembira Ria Kabupaten Muaro Jambi Tahun 2017. Riset Informasi Kesehatan, Vol. 7, No. 1. Juni 2018.

Suripto., S., R. Perancangan Alat Bantu Las Listrik Dengan Teknik Pengelasan Dua Sisi Berdasarkan Prinsip Ergonomi. Skripsi Teknik Industri Universitas Sebelas Maret. Januari 2011. (Tidak Dipublikasikan).

Setiawan, A. Perancangan Kursi Operator Cold Shear Dengan Pendekatan Ergonomi Antrophometri Dan Analytical Hierarchy Process Di PT. Ispat Panca Putera. Jurnal MATRIK, Vol. 18, No. 1. September 2017.

Sugiharto dan Astutik., S. Hubungan Antara Desain Kursi Kerja Dengan Keluhan Nyeri Punggung Bawah Pada Pekerja Bagian Penenunan Di Cv. Pirsa Art Pekalongan. Unnes Jurnal Of Republic Health. 2015.

Wibisono., Lukman., M., dan Resuputri., D., P. Metode REBA Untuk Pencegahan Musculoskeletal Disorder Tenaga Kerja. Jurnal Teknik Industri, Vol. 18, No. 1. Februari 2017. 